\title{
Updates in Interventional Pulmonology 2013
}

\section{Hans J Lee*}

Interventional Pulmonology, Johns Hopkins University, USA

The emerging sub-specialty of Interventional Pulmonology (IP) had an explosive year in 2013. There had been significant progress in research, education, and the specialty in general. The field of IP had been evolving since the 1990's with the resurrection of rigid bronchoscopy and the application of technology from other fields such as gastroenterology, interventional radiology, and thoracic surgery. Currently, new technology is being developed for not only pulmonology, but specifically for IP.

Procedurally, we are seeing new advances in both existing procedures and novel procedure for common pulmonary diseases. Cryo therapy has become popularized with the recent pilot study of larger lung biopsies compared to traditional forceps biopsy for postlung transplant surveillance [1]. Traditionally, surgical lung biopsies were needed to establish certain diagnosis due to the inadequacy of smaller bronchoscopic biopsy fragments, this study opens the potential gateway to an alternative of surgical biopsies. We have also seen a randomized clinical trial (TIME2 trial) showing equivalence of tunneled pleural catheters and talc pleurodesis for relieving dyspnea [2]. The significance of this trial is the rigorous methodology to offer patients with malignant pleural effusions options for their effusion management.

This year, we saw the initiation of three different pivotal multicenter trials in the USA evaluating different technologies for bronchoscopic lung volume reduction for advance emphysema. Most of these trials are considered second-generation devices with different methods to overcome collateral ventilation, which had made prior devices less effective. The RENEW trial started enrollment using nitinoil coils, ASPIRE trial using foam sealants, and the extension of the Spiration IBV, unidirectional bronchial valves.

There were two educational tools validated; IP didactic examination and EBUS STAT [3,4].The EBUS STAT allows for practioners to measure and evaluate progress to competency for EBUS bronchoscopy.
With the widespread dissemination of EBUS, tools like EBUS stat are needed to measure competency. The validation of an IP exam measuring IP didactic knowledge is also important for competency. This study also showed a significant knowledge difference between IP and general pulmonary fellowship graduates which suggests a disparity in didactic knowledge.

2013 will be the first year for an IPBoard Certification exam, which is sponsored throughthe American Association of Bronchology and Interventional Pulmonology (AABIP). In any sub-specialty, a defined qualification that is measurable needs to exist. IP practitioners and the public will finally have criteria for competency in IP. Scholastically, the dedicated journal for IP, Journal of Bronchology and Interventional Pulmonology was included by Index Medicus [5].This is the first dedicated IP journal to reach this status and is a reflection of the science within IP.

This year's advancement in IP will sets the stage for an even more exciting year for the future of IP.

\section{References}

1. Yarmus L, Akulian J, Gilbert C, Illei P, Shah P, et al. (2013) Cryoprobe transbronchial lung biopsy in patients after lung transplantation: a pilot safety study. Chest 143: 621-626.

2. Davies HE, Mishra EK, Kahan BC, Wrightson JM, Stanton AE, et al. (2012) Effect of an indwelling pleural catheter vs chest tube and talc pleurodesis for relieving dyspnea in patients with malignant pleural effusion: the TIME2 randomized controlled trial. JAMA 307: 2383-2389.

3. Davoudi M, Colt HG, Osann KE, Lamb CR, Mullon JJ (2012) Endobronchial ultrasound skills and tasks assessment tool: assessing the validity evidence for a test of endobronchial ultrasound-guided transbronchial needle aspiration operator skill. Am J Respir Crit Care Med 186: 773-779.

4. Lee HJ, Feller-Kopman D, Shepherd RW, Almeida FA, Bechara R, et al. (2013) Validation of an Interventional Pulmonary Examination. Chest.

5. Feller-Kopman D (2013) A Milestone for the JOBIP. J Bronchology Interv Pulmonol 20: 3.
*Corresponding author: Hans J Lee, MD, Assistant Professor of Medicine Interventional Pulmonology, Johns Hopkins University, 1800 Orleans St., Suite 7125L, Baltimore, MD 21287, USA, Tel: 410 502-2533; E-mail: Hlee171@jhmi.edu

Received May 24, 2013; Accepted May 27, 2013; Published May 29, 2013

Citation: Lee HJ (2013) Updates in Interventional Pulmonology 2013. J Pulm Respir Med 3: e126. doi:10.4172/2161-105X. 1000e126

Copyright: @ 2013 Lee HJ. This is an open-access article distributed under the terms of the Creative Commons Attribution License, which permits unrestricted use, distribution, and reproduction in any medium, provided the original author and source are credited. 